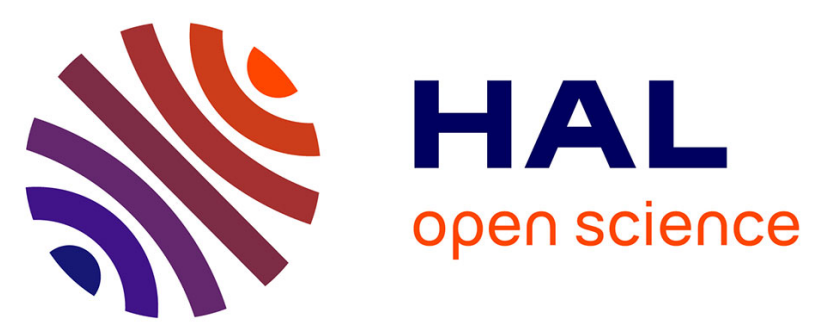

\title{
Membrane modules for CO2 capture based on PVDF hollow fibers with ionic liquids immobilized
}

L. Gomez-Coma, A. Garea, Jean-Christophe Rouch, Thibaud Savart, J.-F. Lahitte, Jean-Christophe Remigy, A. Irabien

\section{- To cite this version:}

L. Gomez-Coma, A. Garea, Jean-Christophe Rouch, Thibaud Savart, J.-F. Lahitte, et al.. Membrane modules for CO2 capture based on PVDF hollow fibers with ionic liquids immobilized. Journal of Membrane Science, 2016, 498, pp.218-226. 10.1016/j.memsci.2015.10.023 . hal-01285930

\section{HAL Id: hal-01285930 \\ https://hal.science/hal-01285930}

Submitted on 10 Mar 2016

HAL is a multi-disciplinary open access archive for the deposit and dissemination of scientific research documents, whether they are published or not. The documents may come from teaching and research institutions in France or abroad, or from public or private research centers.
L'archive ouverte pluridisciplinaire HAL, est destinée au dépôt et à la diffusion de documents scientifiques de niveau recherche, publiés ou non, émanant des établissements d'enseignement et de recherche français ou étrangers, des laboratoires publics ou privés. 


\section{OATAO}

\section{Open Archive TOULOUSE Archive Ouverte (OATAO)}

OATAO is an open access repository that collects the work of Toulouse researchers and makes it freely available over the web where possible.

This is an author-deposited version published in : http://oatao.univ-toulouse.fr/ Eprints ID : 15576

To link to this article : DOI:10.1016/j.memsci.2015.10.023

URL : http://dx.doi.org/10.1016/j.memsci.2015.10.023

To cite this version : Gomez-Coma, L. and Garea, A. and Rouch, J.C. and Savart, T. and Lahitte, J.-F. and Remigy, J.-C. and Irabien, A. Membrane modules for CO2 capture based on PVDF hollow fibers with ionic liquids immobilized. (2016) Journal of Membrane Science, vol. 498. pp. 218-226. ISSN 03767388

Any correspondence concerning this service should be sent to the repository administrator: staff-oatao@,listes-diff.inp-toulouse.fr 


\title{
Membrane modules for $\mathrm{CO}_{2}$ capture based on PVDF hollow fibers with ionic liquids immobilized
}

\author{
L. Gomez-Coma ${ }^{\mathrm{a}, *}$, A. Garea ${ }^{\mathrm{a}}$, J.C. Rouch ${ }^{\mathrm{b}, \mathrm{c}}$, T. Savart ${ }^{\mathrm{b}, \mathrm{c}}$, J.F. Lahitte ${ }^{\mathrm{b}, \mathrm{c}}$, J.C. Remigy ${ }^{\mathrm{b}, \mathrm{c}}$, \\ A. Irabien ${ }^{\text {a }}$ \\ a Universidad de Cantabria, Chemical and Biomolecular Engineering Department, E.T.S. de Ingenieros Industriales y Telecomunicación, Avda Los Castros s/n, \\ 39005 Santander, Spain \\ ${ }^{\mathrm{b}}$ Université de Toulouse, INPT, UPS, Laboratoire de Genie Chimique, 118 Route de Narbonne, F-31062 Toulouse, France \\ ${ }^{\mathrm{c}}$ CNRS, Laboratoire de Genie Chimique, F-31030 Toulouse, France
}

Keywords:

Carbon dioxide capture

Membrane contactors

Fibers

PVDF

Ionic liquids (ILs)

\begin{abstract}
A B S T R A C T
Hollow fiber membrane contactors with ionic liquids are promising alternatives to traditional spray towers and amines for carbon dioxide absorption. Ionic liquids have emerged as new alternative solvents because of their zero emission features compared with amines. The aim of this work was to compare fibers based on PVDF and different additives, as well as fibers including two different ionic liquids. On the one hand, 1-ethyl-3-methylimidazolium ethyl sulfate [emim] $\left[\mathrm{EtSO}_{4}\right]$ presents physical absorption, and on the other hand, 1-ethyl-3-methylimidazolium acetate [emim][Ac] presents chemical absorption. To compare the fibers under study, the thickness of the composite fiber was examined using scanning electron microscopy (SEM). The mechanical properties and the bubble point were also evaluated. Permeability tests were conducted, and the gas permeation of the composite hollow fibers was measured using pure $\mathrm{CO}_{2}$. Laboratory-made stainless steel modules were used for the tests. All of the above tests were performed with the fibers in both wet and dry conditions. It was determined that the fibers with the ionic liquid immobilized would be promising for $\mathrm{CO}_{2}$ capture because the $\mathrm{CO}_{2}$ permeance significantly increased. Namely, D+[emim] $\left[\mathrm{EtSO}_{4}\right]$ achieved a $43 \%$ increase compared with the fibers without the addition of the ionic liquid, resulting in a $\mathrm{CO}_{2}$ permeance value of $57040 \mathrm{NL} /\left(\mathrm{h} \mathrm{m}^{2} \mathrm{bar}\right)$, which is higher than the values reported in the literature for PVDF. Moreover, the overall mass transfer coefficient for $\mathrm{CO}_{2}$ capture using the $\mathrm{D}+[\mathrm{emim}][\mathrm{Ac}]$ fibers also presented highly competitive values.
\end{abstract}

\section{Introduction}

Carbon dioxide capture and sequestration (CCS) is currently a major concern globally to reduce the impact on the atmosphere and protect humans against the associated risks. However, $\mathrm{CO}_{2}$ capture is the bottleneck step where efforts have to be applied to develop more sustainable processes from technical and economical perspectives [1].

Post-combustion technology constitutes a strategy for reducing the impact of greenhouse gases from fossil fuels in industrial processes. For this reason, the present work is focused on postcombustion capture. This process route is ideally suited for conventional power stations and energy conversion systems. $\mathrm{CO}_{2}$ at low partial pressure is separated from the gas stream after the fuel has been completely burned [2]. The flue gas from a typical post-

\footnotetext{
* Corresponding author. Fax: +34942 201591.

E-mail address: gomezcomal@unican.es (L. Gomez-Coma).
}

combustion process is composed of $10-15 \% \mathrm{CO}_{2}, 70-75 \% \mathrm{~N}_{2}$ and lower concentrations of other components. In these systems, the temperature in the absorption step reaches between 313 and $348 \mathrm{~K}[3]$.

Traditionally, alkanolamines have been used for carbon dioxide capture due to their high reactivity to $\mathrm{CO}_{2}$ by forming complexes with weak chemical bonds and low cost, achieving an outlet stream with a very low $\mathrm{CO}_{2}$ concentration. The development of more beneficial solvents for the environment is currently a topic of great interest. Ionic liquids (ILs) are one of the promising compounds for $\mathrm{CO}_{2}$ gas recovery [1]. ILs are salts that have an organic cation and an inorganic anion and whose melting point is lower than $373 \mathrm{~K}$, and their vapor pressure is negligible [4,5,6]. Additionally, ILs have good thermal stability, high ionic conductivity and solubility in organic media [7].

The chemisorption of $\mathrm{CO}_{2}$ in ionic liquids containing a carboxylic anion can be a promising alternative to common amine processes [8]. Recently, the literature has shown that ILs 
containing acetate anions possess a high degree of absorption for $\mathrm{CO}_{2}$ across a wide range of temperatures [9]. These types of membranes based on ILs have been used in previous works [9-11]. For this reason, 1-ethyl-3-methylimidazolium acetate, [emim][Ac], is an ideal candidate for $\mathrm{CO}_{2}$ capture. In addition, [emim][Ac] was chosen because of its high $\mathrm{CO}_{2}$ solubility and chemical absorption $[3,4,8,12-14]$. On the other hand, an inexpensive and green solvent for industrial applications is an important feature to consider when choosing an ionic liquid for $\mathrm{CO}_{2}$ absorption. 1-Ethyl-3-methylimidazolium ethyl sulfate, [emim] $\left[\mathrm{EtSO}_{4}\right]$, was selected due to its low viscosity, low toxicity and low cost [15]. $\mathrm{CO}_{2}$ capture processes on an industrial scale require the application of high temperatures to a stripper re-boiler for solvent regeneration and $\mathrm{CO}_{2}$ desorption, which poses a main drawback to the energy consumption. As an alternative, numerous works based on hollow fiber membrane contactors [16] have been reported in recent years because they offer numerous advantages, such as controlled interfacial area, independent control of the gas and liquid flow rates, reduction in solvent losses, much larger contact area per unit volume compared with tray and/or packed columns and no dispersion from one phase into another [16-19]. Additionally, membranes are a promising option for established industrial technologies for gas and liquid separations because of the lower energy cost and smaller footprint requirements in the process operations [20].

Commercially, the most employed separations using membranes include the separation of $\mathrm{O}_{2}$ and $\mathrm{N}_{2} ; \mathrm{H}_{2}$ recovery from mixtures with larger components such as $\mathrm{N}_{2}, \mathrm{CH}_{4}$ and $\mathrm{CO}_{2}$; and the removal of $\mathrm{CO}_{2}$ from natural gas mixtures [21]. Traditionally, when dealing with membrane contactors and porous membrane, the main problem is the wetting of pore which probably occurs for long time (even hours sometime) [22]. With a porous membrane, the liquid and gas phases are separated due to the interface which is fixed at the pore entrance due to the Laplace pressure. This one depends on the interfacial tension, the pore diameter and the contact angle. If the transmembrane pressure is higher than the Laplace pressure ( $\sim 1-2$ bars) the liquid will wet the pore [23]. For long term experiment, the contact angle could change due to the adsorption of molecule at the membrane surface or the chemical degradation of the membrane surface properties. Previous works demonstrated that the wetting is avoided when a dense membrane is coated at the membrane surface [24]. In that case, the liquid and gas phase are physically/mechanically separated so the pressure to push the liquid inside a pore is largely increased up to several bars ( $\sim 8-10$ bars) corresponding to the breakage of the membrane. However, in the case of dense composite hollow fiber, the wetting of the fiber could also occur but in a different way. As water in transfer through the membrane by diffusion and in the vapor state, the gas inside the pore is close to be saturated by water so the water vapor could condense inside the pore. In this work the IL is added inside the pore forming a supported liquid membrane. This membrane is used in a membrane contactor so it is a non-porous membrane. To be wetted by water, the water should push the IL. The transmembrane pressure should be higher than the Laplace pressures. The higher viscosity of ionic liquid than water acts as a shock absorber during the transient regime (i. e variation of transmembrane pressure with too high pressure) [25]. Also to obtain high permeability with a membrane filled with a liquid, a liquid with a high diffusion coefficient of $\mathrm{CO}_{2}$ and/or with a high $\mathrm{CO}_{2}$ solubility is necessary, for this reason the [emim] [Ac] and [emim] $\left[\mathrm{EtSO}_{4}\right]$ were chosen.

A study of different self-made PVDF fibers with different additives in the non-dispersive absorption of $\mathrm{CO}_{2}$ was performed in a hollow fiber membrane contactor using two different ionic liquids, [emim] $[\mathrm{Ac}]$ and $[\mathrm{emim}]\left[\mathrm{EtSO}_{4}\right]$.

\section{Experimental}

\subsection{Hollow fiber membranes}

Four type of hollow fibers were selected among 200 hollow fibers elaborated by Savart [26] based on their high gas permeability and a high bubble point. The most permeable one were selected. The complete description of the fiber manufacturing method is explained in a previous works [26-28]. The hollow fibers based on polyvinylidene fluoride (PVDF) membranes with different additives called A, B, C, D and were homemade by phase inversion. The HSV900 PVDF grade was kindly provided by Arkema (France), n-methyl-pyrrolidone NMP (Aldrinch-France) was used as a solvent, and LiCl (Aldrich-France) and a block copolymer were used as additives. The copolymer was a 1-2 diblock copolymer. 1 was a hydrophobic block composed of poly(methyl methacrylate) (75 wt\% of the total mass). 2 was a hydrophilic block composed of poly(butyl acrylate) (20 wt\%) and hydroxyethylmethacrylate (5 wt\%) [26-28]. The dope solutions to make the A and B fibers were composed of 15\% PVDF HSV900 and 3\% LiCl. The C fibers were composed of 15\% PVDF HSV900, 3\% block copolymer and $3 \% \mathrm{LiCl}$. Finally, the D fibers were composed of $15 \%$ PVDF HSV900, 3\% block copolymer, 3\% LiCl and 1\% water [26,27].

The operating parameters used to produce the hollow fibers are shown in Table 1 . The letter $Q$ indicates the flow rate $\left(Q_{\text {collodion: }}\right.$ :

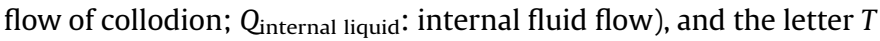
indicates the temperature. The only difference between $\mathrm{A}$ and $\mathrm{B}$ fibers was the internal fluid flow, 1.8 and $3.9 \mathrm{~mL} \mathrm{~min}^{-1}$ respectively. In the case of the D fiber, $1 \%$ of water was immobilized in the doping solution. For this reason, the membranes were different due to the presence or absence of water in the doping solution and due to the different operating conditions. During formation of the membranes, the $\mathrm{LiCl}$ was eliminated during the water-washing step, so the A and B fibers were only composed of PVDF [26]. The block copolymer was partially eliminated; however, the final copolymer content in the fiber was not measured; after the coagulation step that occurs classically with the phase inversion techniques, the block copolymer was found in the coagulation bath, after extraction from water with IR and NMR analysis. Further analysis with secondary ion mass spectrometry (SIMS) technology showed that the copolymer was present in the fiber at the surface of the polymer but also inside the PVDF matrix [26]. Therefore, different quantities of the copolymer could be found in the two hollow fibers.

For drying, the fibers were maintained for approximately $72 \mathrm{~h}$

Table 1

Operating conditions for manufacturing hollow fibers.

\begin{tabular}{|c|c|c|c|c|c|c|c|c|}
\hline & $Q_{\text {collodion }}(\mathrm{mL} / \mathrm{min})$ & $Q_{\text {Internal liquid }}(\mathrm{mL} / \mathrm{min})$ & Composition Internal liquid (mass ratio) & $T_{\text {collodion }}(\mathrm{K})$ & $T_{\text {bath coagulation }}(\mathrm{K})$ & $T_{\text {Internal liquid }}(\mathrm{K})$ & Air gap $(\mathrm{cm})$ & Speed $(\mathrm{m} / \mathrm{min})$ \\
\hline A & 7.2 & 1.8 & Water/NMP 70/30 & 350 & 322 & 351 & 10 & 11 \\
\hline B & 7.2 & 3.9 & Water/NMP 70/30 & 350 & 322 & 351 & 10 & 11 \\
\hline $\mathrm{C}$ & 7.2 & 1.8 & Water/NMP 85/15 & 308 & 333 & 308 & 10 & 11 \\
\hline $\mathrm{D}$ & 7.2 & 1.8 & Water/NMP 70/30 & 323 & 323 & 323 & 32 & 11 \\
\hline
\end{tabular}


in an oven at a temperature of $50{ }^{\circ} \mathrm{C}$ and at atmospheric pressure. Subsequently, new fibers were produced by adding the ILs. The ILs were included into the fibers adding $150 \mathrm{~mL}$ of each ionic liquid into virgin fibers and ILs were immobilized into wet virgin fibers for $48 \mathrm{~h}$. 1-Ethyl-3-methylimidazolium ethyl sulfate [emim] [EtSO ( $\geq 95 \%)$ and 1-ethyl-3-methylimidazolium acetate [emim][Ac] ( $\geq 90 \%$ ) were supplied by SigmaAldrich. Previous authors reported fibers impregnated with ionic liquids $[29,30]$.

To ensure that the ionic liquid was suitable for our process despite its relatively low purity, the solubility rates were measured, and compared with literature data, similar values were obtained [12,31,32].

The membrane contactors were manufactured by gluing hollow fibers in a PVC shell.

\subsection{Characterization techniques for the hollow fiber membranes}

\subsubsection{Scanning electron microscopy}

The thickness of the composite fiber was examined by scanning electron microscopy (SEM; Hitachi TM1000, Tokyo, Japan). The fibers were first immersed in ethanol, cryofractured in liquid nitrogen, and then sputtered with gold. The thickness was measured from the SEM cross-sectional image.

\subsubsection{Mechanical properties of the fibers}

The mechanical properties of the porous supports were measured using a tensile testing device (INSTRON, Model 3342). The calculations of the deformation due to traction and compression, as well as the elasticity, were performed using the Bluehill program (Bluehill 2 Software, Instron). To obtain information about the mechanical properties of the membranes, the tensile strength $(\mathrm{MC})$, tensile strain at break (CC) and elongation at the elastic limit $\left(\varepsilon_{\mathrm{b}}\right)$ were determined from the results of the tension tests.

\subsubsection{Permeation tests}

The gas permeation of the composite hollow fibers was measured using pure $\mathrm{CO}_{2}$. Laboratory-made stainless steel modules were used for these tests. Three fibers approximately $30 \mathrm{~cm}$ long were assembled in each module. The gas was fed into the shell side, and the gas permeation flux was measured at the outlet of the lumen side thanks to a mass flow controller (Brooks Instrument MFC 5850, Emerson Process Management Spain). The pressure was increased in steps of 0.5 bar from 0 to 15 bar. Each measurement was recorded after $100 \mathrm{~s}$ of flux stabilization and was replicated twice under the same operating conditions. Fig. 1 shows the setup for the gas permeability experiments.

\subsubsection{Bubble point}

To measure the bubble point, fibers were prepared and

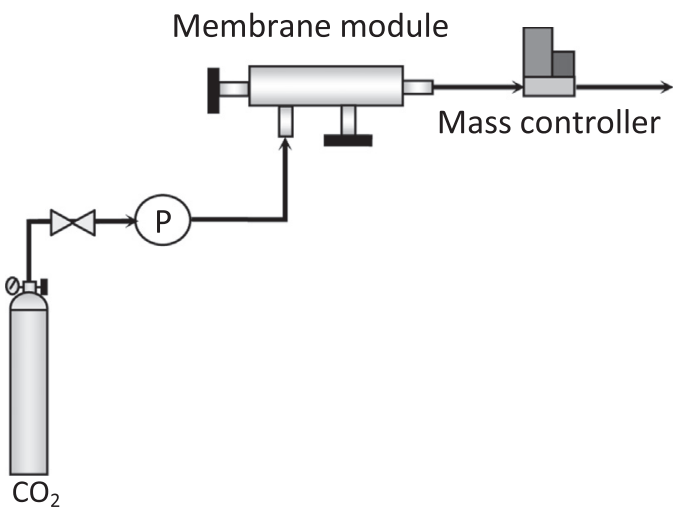

Fig. 1. Experimental setup for gas permeability testing. submerged in water while compressed air was injected in the fiber lumen. The gas pressure was increased from 0 to 7.16 bar with a step of 0.1 bar while keeping the water side at atmospheric pressure. When the first bubble emerged, the bubble point pressure was determined.

\section{3. $\mathrm{CO}_{2}$ capture process}

The experimental setup is shown in Fig. 2. The feed gas mixture stream contained 15 vol\% $\mathrm{CO}_{2}$ and $\mathrm{N}_{2}$ (to balance) and was adjusted using a mass flow controller (Brooks Instrument MFC 5850, Emerson Process Management Spain). Gas stream flowed through the inside of the hollow fibers. The gas flow rate was $20 \mathrm{~mL} \mathrm{~min}^{-1}$. The ionic liquid 1-ethyl-3- methylimidazolium acetate flowed in counter-current through the shell side. The IL was pumped from the storage tank. Control and measurement in the liquid line $\left(50 \mathrm{~mL} \mathrm{~min}^{-1}\right.$ ) were achieved using a digital gear pump (Cole Parmer Instrument Company, Hucoa-Erloss S.A, Spain).

The experiments were performed over the temperature range of 303-333 K. Each experiment was replicated three times under the same operating conditions, and the average value was calculated. During the operation with these ionic liquids, their properties were stable and no loss was observed with time. Previous works have also reported that [emim][Ac] and [emim][EtSO 4 can be regenerated without losing their properties [12].

To obtain isothermal conditions, an oven was introduced in the experimental setup, as shown in Fig. 2.

The carbon dioxide concentration in the outlet gas stream was continuously monitored by sampling a fraction of the stream through a gas analyzer (Emerson Process, Rosemount Analytical NGA 2000) based on non-dispersive infrared (NDIR) spectroscopy. Before sending the gas sample to the analyzer, it was necessary to dilute the sample with $\mathrm{N}_{2}$ to maintain the concentration range for the NDIR analyzer (at least $200 \mathrm{~mL} \mathrm{~min}^{-1}$ ). Steady state was indicated by a constant $\mathrm{CO}_{2}$ concentration in the exit gas stream.

\section{Results and discussion}

\subsection{Results of characterization of the hollow fiber membranes}

Table 2 shows the measurements of the inner diameter $\left(d_{\mathrm{i}}\right)$, wall thickness $(e)$, and length $(L)$ for fibers in the wet and dry forms. The virgin fibers shrank by approximately $5 \%$ of their length as they dried. Note that in the case of the D fibers, both the inner diameter and the wall thickness decreased in the dry form, possibly due to the contraction of the polymer phase. The greatest variation occurred in the A fibers. In the dry form, the $C$ and $D$ fibers presented the highest wall thicknesses.

The mechanical properties results are compiled in Table 3. Note that the B fibers showed the highest elasticity.

Regarding the permeability results with pure $\mathrm{CO}_{2}$, the behavior of the wet fibers was affected by the relative humidity (Fig. 3). A fibers in wet form suffer a compaction around 2 bars and the $\mathrm{CO}_{2}$ flux is smaller than $B$ and $C$ fibers. The trend in the case of this last type of fibers ( $B$ and $C$ ) is linear reaching fluxes of more than $1.2 \cdot 10^{5} \mathrm{NL} \mathrm{m}^{-2} \mathrm{~h}^{-1}$ with 6 and 7 bar respectively.

Fig. 4 shows the permeability results with pure $\mathrm{CO}_{2}$ and dry fibers. On the one hand, a high permeability and a linear trend were observed in the $\mathrm{C}$ and $\mathrm{D}$ fibers in dry form, which presented almost identical $\mathrm{CO}_{2}$ permeabilities. No compaction was observed up to 4 bars in these type of fibers. On the other hand, the results obtained with the A and B fibers indicated that the permeability was very low. The compaction of the fibers occurred at 2 bars for the A fibers as the previous case, mentioned in Fig. 3. The $\mathrm{CO}_{2}$ flux with wet fibers was considerably higher than with dry fibers in 


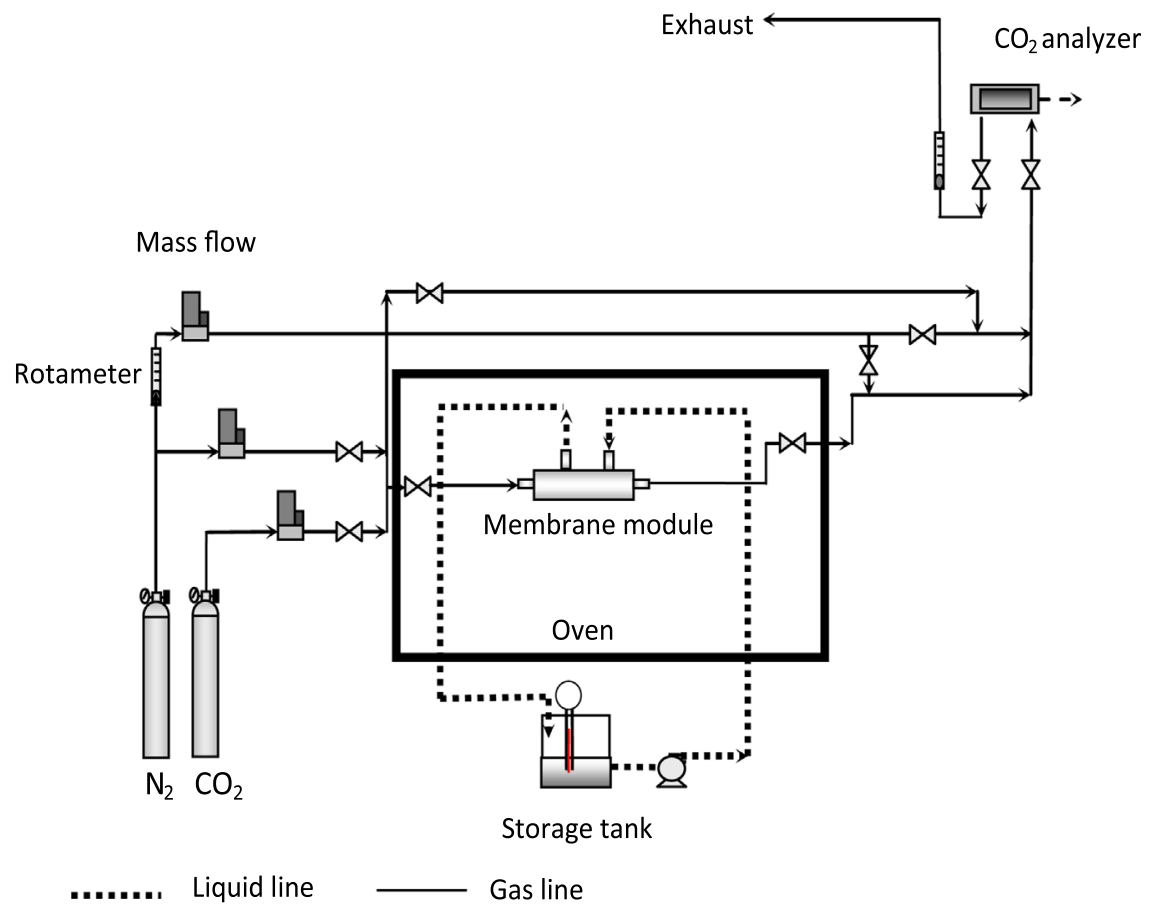

Fig. 2. Experimental setup for $\mathrm{CO}_{2}$ gas capture.

Table 2

Outer diameter, wall thickness and length of PVDF hollow fibers with different additives and with ionic liquid immobilized.

\begin{tabular}{|c|c|c|c|c|c|c|}
\hline & \multicolumn{3}{|l|}{ Dry } & \multicolumn{3}{|l|}{ Wet } \\
\hline & $d_{\mathrm{i}}(\mathrm{mm})$ & $e(\mu \mathrm{m})$ & $L(\mathrm{~cm})$ & $d_{\mathrm{i}}(\mathrm{mm})$ & $e(\mu \mathrm{m})$ & $L(\mathrm{~cm})$ \\
\hline A & 0.739 & 90 & 78,5 & 0.484 & 139 & 82.6 \\
\hline B & 0.584 & 109 & 78.6 & 0.572 & 101 & 82.6 \\
\hline $\mathrm{C}$ & 0.488 & 157 & 78.6 & 0.410 & 137 & 82.6 \\
\hline $\mathrm{D}$ & 0.455 & 174 & 78.9 & 0.475 & 184 & 82.6 \\
\hline \multicolumn{7}{|c|}{ Ionic liquid embedded } \\
\hline $\mathrm{C}+[\mathrm{emim}]\left[\mathrm{EtSO}_{4}\right]$ & 0.439 & 143 & 84.2 & 0.496 & 154 & 82.5 \\
\hline $\mathrm{C}+[\mathrm{emim}][\mathrm{Ac}]$ & 0.436 & 151 & 82.0 & 0.515 & 165 & 82.5 \\
\hline $\mathrm{D}+[\mathrm{emim}]\left[\mathrm{EtSO}_{4}\right]$ & 0.443 & 159 & 85.3 & 0.379 & 146 & 82.5 \\
\hline $\mathrm{D}+[\mathrm{emim}][\mathrm{Ac}]$ & 0.451 & 160 & 81.7 & 0.472 & 172 & 82.5 \\
\hline
\end{tabular}

The maximum standard deviation between measurements is $5.88 \%$.

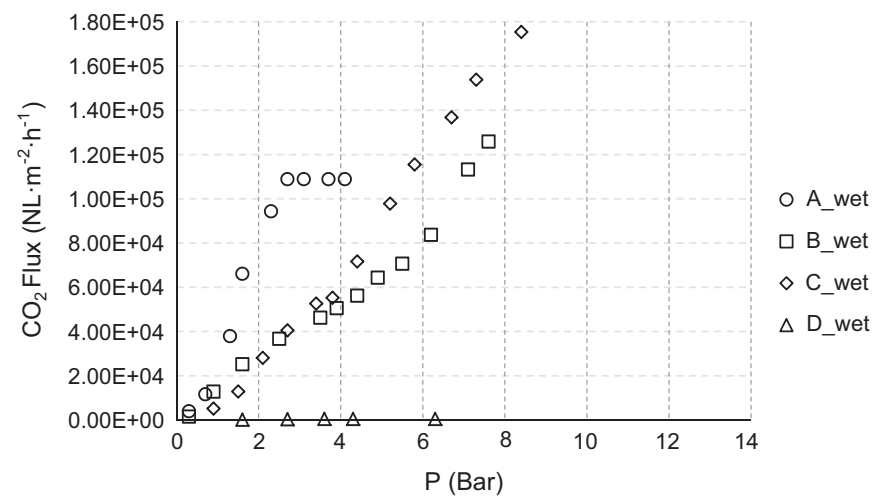

Fig. 3. Permeability results with wet fibers.

Table 3

Mechanical properties of PVDF hollow fibers with different additives and with ionic liquid immobilized.

\begin{tabular}{|c|c|c|c|c|c|c|c|c|}
\hline & \multicolumn{4}{|l|}{ Dry } & \multicolumn{4}{|l|}{ Wet } \\
\hline & $\mathrm{MC}(\mathrm{N})$ & CC (Mpa) & $\mathcal{E}_{\mathrm{b}}(\%)$ & $E\left(\mathrm{~N} / \mathrm{mm}^{2}\right)$ & $\mathrm{MC}(\mathrm{N})$ & CC (Mpa) & $\varepsilon_{\mathrm{b}}(\%)$ & $E\left(\mathrm{~N} / \mathrm{mm}^{2}\right)$ \\
\hline A & 1.62 & 7.90 & 150.38 & 161.82 & 1.60 & 5.91 & 158.68 & 47.50 \\
\hline B & 1.61 & 6.23 & 150.53 & 135.33 & 1.62 & 7.58 & 181.53 & 92.70 \\
\hline C & 2.07 & 6.53 & 74.89 & 188.23 & 1.88 & 8.00 & 76.67 & 180.74 \\
\hline $\mathrm{D}$ & 1.95 & 5.67 & 50.03 & 183.11 & 1.78 & 4.68 & 63.71 & 98.11 \\
\hline \multicolumn{9}{|l|}{ Ionic liquid embedded } \\
\hline $\mathrm{C}+[\mathrm{emim}]\left[\mathrm{EtSO}_{4}\right]$ & 1.37 & 5.25 & 142.42 & 12.36 & 1.35 & 4.29 & 145.53 & 18.29 \\
\hline $\mathrm{C}+[\mathrm{emim}][\mathrm{Ac}]$ & 1.56 & 5.61 & 116.89 & 81.86 & 1.60 & 4.40 & 128.05 & 40.03 \\
\hline $\mathrm{D}+[\mathrm{emim}]\left[\mathrm{EtSO}_{4}\right]$ & 1.26 & 4.18 & 142.92 & 9.28 & 1.28 & 5.32 & 168.33 & 65.40 \\
\hline $\mathrm{D}+[\mathrm{emim}][\mathrm{Ac}]$ & 1.49 & 4.87 & 95.32 & 68.42 & 1.47 & 4.20 & 110.12 & 41.94 \\
\hline
\end{tabular}

The maximum standard deviation between measurements is $6.4 \%$.

both cases.

Taking into account the high permeability results, the $C$ and $D$ fibers were the most appropriate for the addition of the ionic liquids and consequently for $\mathrm{CO}_{2}$ absorption.

\subsection{Results of characterization of selected hollow fibers when Ionic}

liquids were immobilized

Tables 4 and 5 show the structural comparison with or without IL for the two ionic liquids using scanning electron microscopy. The virgin fibers were wet; therefore, the fibers were dried after adding the IL. In the case of $\mathrm{D}+[\mathrm{emim}]\left[\mathrm{EtSO}_{4}\right]$, the results were 


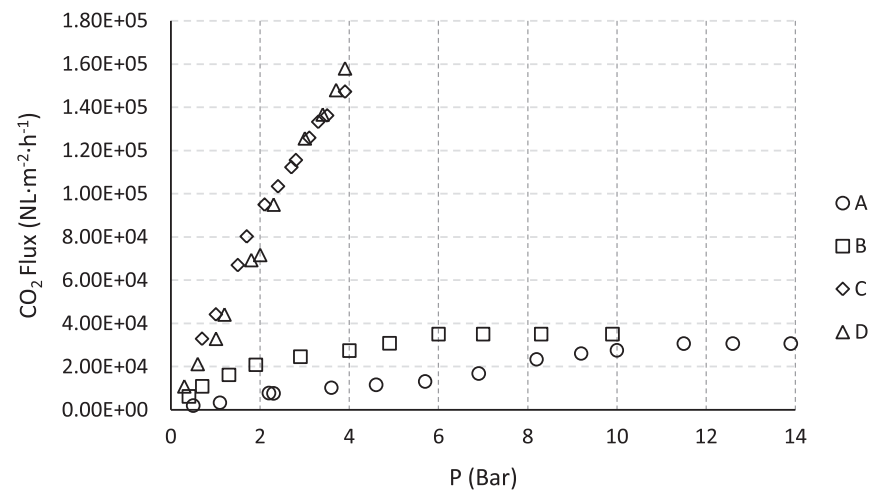

Fig. 4. Permeability results with dry fibers.

highly different in the wet form because the inner and outer diameters decreased (Table 2 ). The results with $\mathrm{D}+[\mathrm{emim}][\mathrm{Ac}]$ were similar. In the wet form, the fibers when the ionic liquid was added, the pores were filled and possibly creating a new layer, as shown in Table 4 . The $\mathrm{C}$ fibers immobilized with ionic liquids showed an increment in the diameters in the wet form (Table 2). This result could be primarily attributed to the fact that the ionic liquids swelled the virgin fibers and dissolved the polymeric matrix in the case of the $\mathrm{C}+[\mathrm{emim}]\left[\mathrm{EtSO}_{4}\right]$ and $\mathrm{C}+[\mathrm{emim}][\mathrm{Ac}]$ fibers, as shown in Table 5.

The fiber sizes (Table 2) were in accordance with the literature. Rezaei et al. prepared their own fibers with inner and outer diameters of $0.455 \pm 0.025$ and $0.825 \pm 0.025 \mathrm{~mm}$, respectively [33]. Meanwhile, Naim et al. obtained fibers with $d_{\mathrm{i}}=0.550 \pm 0.020 \mathrm{~mm}$ and $d_{\mathrm{o}}=0.800 \pm 0.030 \mathrm{~mm}$ [34].

Table 3 shows the results of the mechanical properties of the fibers with and without ionic liquids. The breaking strain suffered significant changes. $\mathrm{C}+[\mathrm{emim}]\left[\mathrm{EtSO}_{4}\right]$ and $\mathrm{C}+[\mathrm{emim}][\mathrm{Ac}]$ fibers obtained values $50 \%$ smaller than without ionic liquids in wet form. Results in dry form with ILs show a decrease around $17 \%$ and $26 \%$ with C and D fibers respectively. On the other hand, note that the deformation in these modified fibers was at least two-fold greater when the ionic liquids were immobilized. The compression with the $\mathrm{C}$ fibers and the ionic liquids was much lower than without ILs. Young's modulus $\left(\mathrm{N} / \mathrm{mm}^{2}\right)$ was calculated using Eq. (1).

$E=\frac{\sigma}{\epsilon}=\frac{\frac{F}{S}}{\frac{\Delta L}{L}}$

where $E$ is Young's modulus (modulus of elasticity), $F$ is the force exerted on an object under tension (fiber), $\Delta L$ is the amount by which the length of the fiber changes, $L$ is the original length of the fiber, and $\mathrm{S}$ is the fiber section.

Young's modulus decreased in the presence of IL, indicating that there was an interaction between the IL and the polymeric matrix. The IL plasticized the polymer, and the fiber swelled.

The bubble point results are presented in Table 6 . The results with the $\mathrm{D}$ fibers did not lead to any definitive conclusions because they exceeded the maximum measured value of the equipment (7.1 bar). Furthermore, the results with the $C$ fibers indicated that in the case of [emim] $\left[\mathrm{EtSO}_{4}\right]$, the bubble point was higher than in the case of fibers without ionic liquid, 6.4 and 4.9 bar respectively. Slightly lower values were obtained with $\mathrm{C}+[\mathrm{emim}][\mathrm{Ac}]$ fibers ( 4.4 bar). These bubble points show the transmembrane pressure necessary to push the IL outside of the pore. This work achieves pressure quite high compared to the transmembrane pressure in a $\mathrm{G} / \mathrm{L}$ contactors reported in the literature [35-37].

The results of the $\mathrm{CO}_{2}$ permeation tests with fibers in dry form are listed in Figs. 5 and 6 for the C and D fibers, respectively, showing the differences produced when the ionic liquids were immobilized. A change in dimensions of the fibers when the ILs were added does not necessarily mean more or less permeability (Figs. 5 and 6). The dotted lines accompanying each graph showed a clear linear trend. On one hand when $C$ fibers were studied the confidence reached $R^{2}=0.99$ when the ionic liquids were added and $R^{2}=0.97$ without ionic liquids. On the other hand results with D fibers reported a confidence of $R^{2}=0.98$ and $R^{2}=0.99$ with [emim] $\left[\mathrm{EtSO}_{4}\right]$ ionic liquid and without IL respectively.

When fibers $C$ and $\mathrm{D}$ were used the permeability with the ionic liquid $[\mathrm{emim}]\left[\mathrm{EtSO}_{4}\right]$ increased in both cases. In the case of $\mathrm{C}+$ [emim] $\left[\mathrm{EtSO}_{4}\right]$ the flux achieved a value of $46679 \mathrm{NL} \mathrm{m}^{-2} \mathrm{~h}^{-1}$ and

Table 4

Scanning electron microscopy images of the D fibers with ionic liquid immobilized.

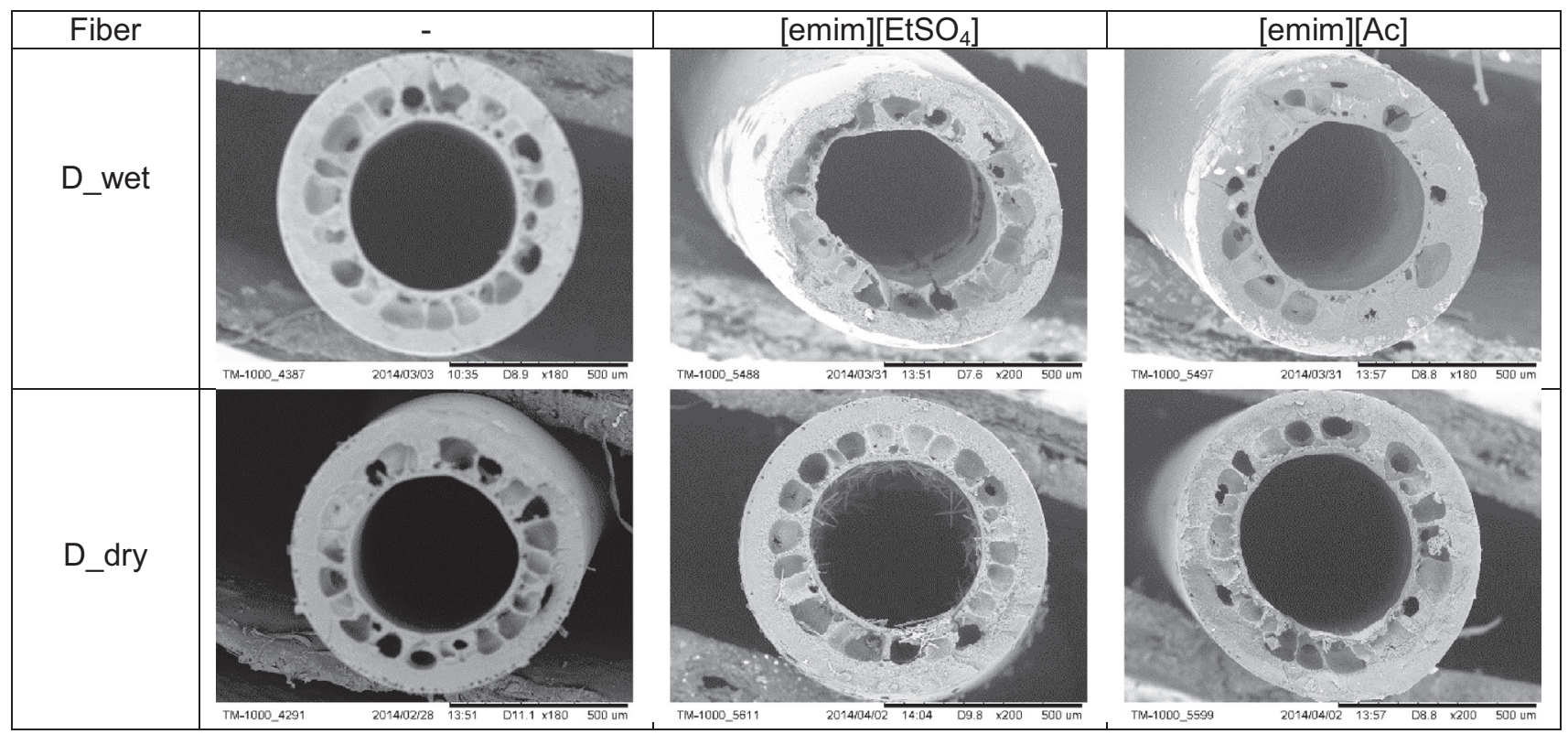


Table 5

Scanning electron microscopy images of the $\mathrm{C}$ fibers with ionic liquid immobilized.

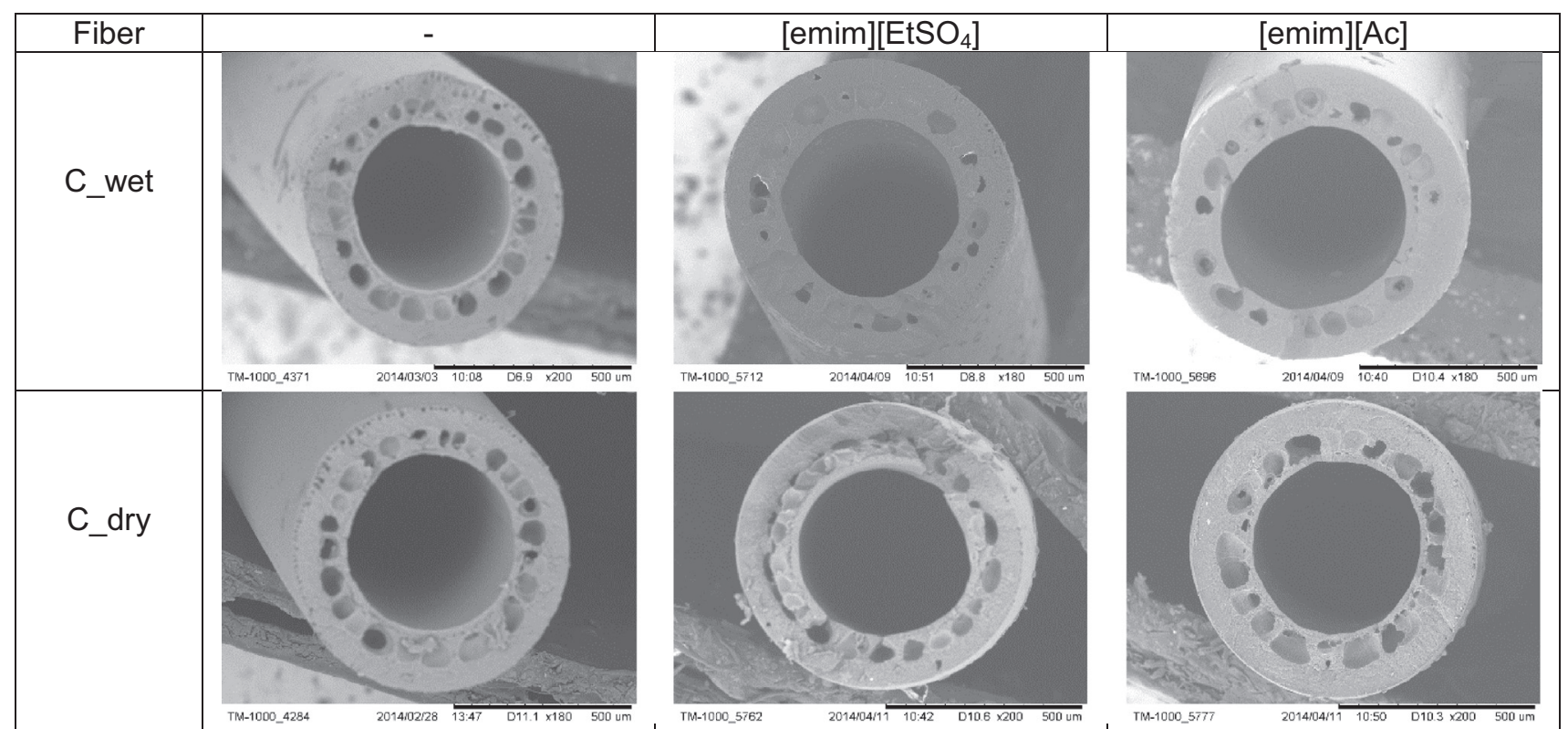

Table 6

Bubble point results of the $\mathrm{C}$ and $\mathrm{D}$ fibers with ionic liquids immobilized.

\begin{tabular}{ll}
\hline Fiber & Bubble point P (Bar) \\
\hline C & 4.9 \\
C $+[$ emim $]\left[\mathrm{EtSO}_{4}\right]$ & 6.4 \\
C $+[$ emim $][\mathrm{Ac}]$ & 4.4 \\
$\mathrm{D}$ & $>7.1$ \\
$\mathrm{D}+[\mathrm{emim}]\left[\mathrm{EtSO}_{4}\right]$ & $>7.1$ \\
$\mathrm{D}+[\mathrm{emim}][\mathrm{Ac}]$ & $>7.1$ \\
\hline
\end{tabular}

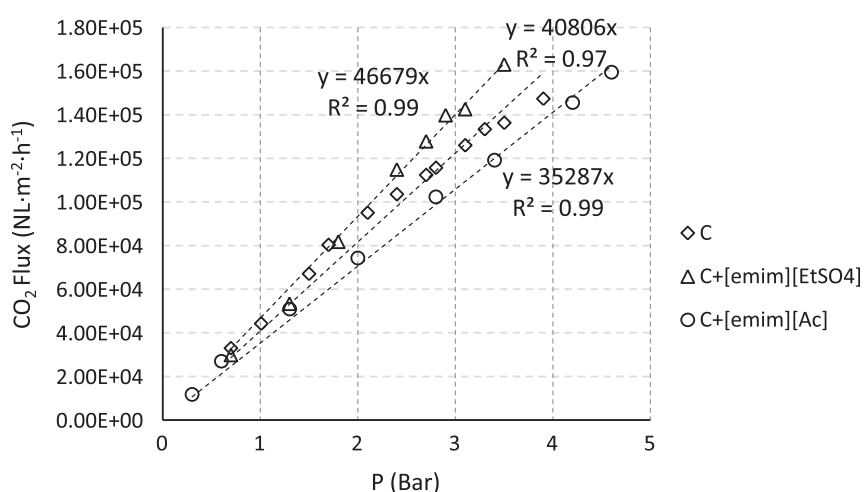

Fig. 5. Permeability results with the $C$ fibers and with ionic liquids immobilized.

in the case of $\mathrm{D}+[\mathrm{emim}]\left[\mathrm{EtSO}_{4}\right]$ the value was $57041 \mathrm{NL} \mathrm{m}^{-2} \mathrm{~h}^{-1}$. The tests for permeability from 0 to 14 bar with $\mathrm{CO}_{2}$ using the $\mathrm{D}$ fibers with the ionic liquid [emim] $[\mathrm{Ac}]$ in dry form did not result in any values, which could be attributed to the fact that the ionic liquid filled the pores, and thus, the gas was unable to enter fibers. The explanation may be related to the contraction observed in the pores of the fibers, which may cause that $\mathrm{CO}_{2}$ cannot enter the fiber. Further work will be planned to confirm this point.

Table 7 shows the calculated $\mathrm{CO}_{2}$ permeance values, in which the obtained values from previous works are also compiled $[22,24,28,38,39]$. The important points to note are as follows:

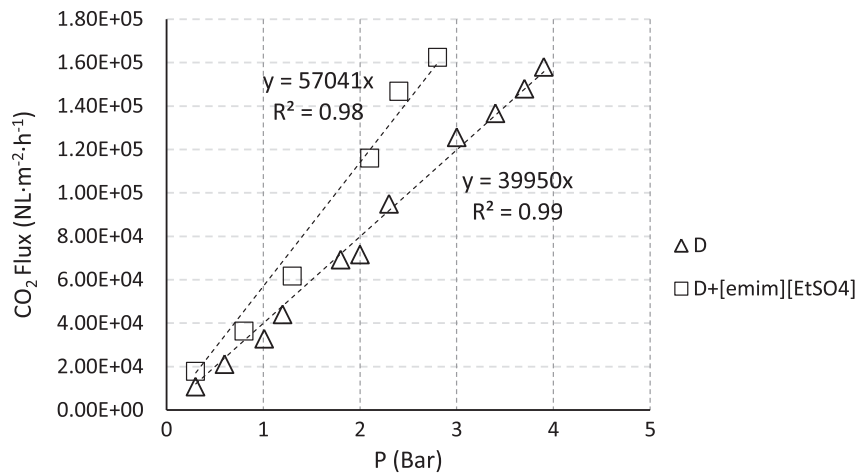

Fig. 6. Permeability results with the D fibers, and with ionic liquid immobilized.

Table 7

$\mathrm{CO} 2$ permeance values.

\begin{tabular}{lll}
\hline Hollow fibers & $\mathrm{CO}_{2}\left(\mathrm{NL} /\left(\mathrm{h} \mathrm{m}^{2}\right.\right.$ bar $\left.)\right)$ & Reference \\
\hline PVDF C (dry) & 40806 & This work \\
PVDF C+[emim][EtSO 4$]($ dry $)$ & 46679 & This work \\
PVDF $C+[$ emim][Ac] $($ dry $)$ & 35287 & This work \\
PVDF D (dry) & 39950 & This work \\
PVDF D+[emim][EtSO 4$]($ dry) & 57041 & This work \\
PTMSP & $5580-3070$ & {$[24]$} \\
Teflon AF2400 & $5900-4590$ & {$[24]$} \\
PVDF $($ Water/NMP/PVA) & $53200-365$ & {$[28]$} \\
PES_PTMSP & $8915-5588$ & {$[22]$} \\
PES_Teflon AF2400 & $9930-6000$ & {$[22]$} \\
Oxyplan_PTMSP & 3070 & {$[22]$} \\
Oxyplan_Teflon AF2400 & 5120 & {$[22]$} \\
TPX & $2710-1350$ & {$[38]$} \\
PSF 5\% packing density & 44200 & {$[39]$} \\
\hline
\end{tabular}

(i) the hollow fibers immobilized with the ionic liquid [emim] $\left[\mathrm{EtSO}_{4}\right]$ presented higher values of $\mathrm{CO}_{2}$ permeance $(43 \%$ increase compared with the fibers without the addition of the ionic liquid) for the PVDF fibers denoted $\mathrm{D}$, and (ii) the highest $\mathrm{CO}_{2}$ permeance value, $57040 \mathrm{NL} /\left(\mathrm{h} \mathrm{m}^{2}\right.$ bar), exceeded the reported values for PVDF and Teflon self-made hollow fibers. 
Table 8

$\mathrm{CO}_{2}$ capture experiments ( $15 \% \mathrm{CO}_{2}$ gas phase and membrane module) with the $\mathrm{D}+[\mathrm{emim}][\mathrm{Ac}]$ PVDF fibers.

\begin{tabular}{|c|c|c|c|c|c|c|}
\hline$T(\mathrm{~K})$ & Efficiency (\%) & $R_{\text {overall }} \cdot 10^{-4}\left(\mathrm{~s} \mathrm{~m}^{-1}\right)$ & $R_{\mathrm{g}}\left(\mathrm{s} \mathrm{m}^{-1}\right)$ & $R_{\mathrm{m}} \cdot 10^{-2}\left(\mathrm{~s} \mathrm{~m}^{-1}\right)$ & $R_{\mathrm{l}} \cdot 10^{-4}\left(\mathrm{~s} \mathrm{~m}^{-1}\right)$ & $K_{\text {overall }}\left(\mathrm{m} \mathrm{s}^{-1}\right)$ \\
\hline 303 & $20.4 \pm 2.27$ & 6.02 & 7.39 & 1.41 & 6.01 & $1.66 \cdot 10^{-5}$ \\
\hline 313 & $27.1 \pm 3.01$ & 4.37 & 6.98 & 1.33 & 4.35 & $2.29 \cdot 10^{-5}$ \\
\hline 323 & $28.6 \pm 2.47$ & 4.10 & 6.27 & 1.19 & 4.09 & $2.44 \cdot 10^{-5}$ \\
\hline 333 & $29.3 \pm 1.83$ & 3.98 & 5.96 & 1.13 & 3.97 & $2.51 \cdot 10^{-5}$ \\
\hline
\end{tabular}

\subsection{Results of $\mathrm{CO}_{2}$ capture}

$\mathrm{CO}_{2}$ absorption experiments were performed in a PVC membrane contactor to evaluate the process efficiency at different temperatures, working with a gas phase composed of $15 \% \mathrm{CO}_{2}$ and $85 \% \mathrm{~N}_{2}$. Related to the $\mathrm{CO}_{2}$ interaction, the ionic liquid [emim] [EtSO ${ }_{4}$ ] presents physical absorption, while the ionic liquid [emim] [Ac] presents chemical absorption [3,4,8,12-14]. Taking into account this point, the ionic liquid [emim][Ac] was selected for the $\mathrm{CO}_{2}$ capture study in order to show the mass transfer enhanced by the chemical reaction.

The gas stream was fed through the lumen side, while the liquid (1-ethyl-3-methylimidazolium acetate) flowed in countercurrent through the shell-side. A module with $11 \mathrm{D}+$ [emim] [Ac] fibers in the dry form was chosen for $\mathrm{CO}_{2}$ absorption.

The $\mathrm{CO}_{2}$ removal efficiency was calculated as follows:

Efficiency $(\%)=\left(1-\frac{C_{\mathrm{CO}_{2}, \text { out }}}{C_{\mathrm{CO}_{2} \text {, in }}}\right) 100$

Table 8 shows the removal efficiencies determined at different temperatures (303-333 K) with a gas flow rate of $20 \mathrm{~mL} \mathrm{~min}^{-1}$.

The resistance in a series approach could be used to relate the individual mass transfer resistances to the overall mass transfer resistance:

$R_{\text {overall }}=R_{\mathrm{l}}+R_{\mathrm{g}}+R_{\mathrm{m}}$

Table 8 also reports the values of the calculated resistances in the liquid phase, gas phase and membrane respectively $\left(R_{\mathrm{g}}, R_{\mathrm{l}}\right.$ and $R_{\mathrm{m}}$ ), which constitute $R_{\text {overall }}$. The contribution of the gas phase and membrane could be considered negligible, in agreement with previous works $[12,40,41]$. In order to calculate each resistance the Eq. (4) was used.

$\frac{1}{K_{\text {overall }}}=\frac{d_{0}}{k_{\mathrm{g}} d_{\mathrm{i}}}+\frac{d_{0}}{k_{\mathrm{mg}} d_{\mathrm{lm}}}+\frac{1}{k_{\mathrm{l}} H_{\mathrm{d}} E}$

where $d_{\mathrm{o}}, d_{\mathrm{i}}$ and $d_{\mathrm{lm}}$ are the outside, inside and log mean diameters in $(\mathrm{m})$ of the hollow fiber, $H_{\mathrm{d}}$ represents the dimensionless Henry constant, $k_{\mathrm{g}}, k_{\mathrm{mg}}, k_{\mathrm{l}}$, which are the individual mass transfer coefficients of the gas phase, membrane and liquid phase, respectively $\left(\mathrm{m} \mathrm{s}^{-1}\right)$ and $K_{\text {overall }}$ is the overall mass transfer coefficient $\left(\mathrm{m} \mathrm{s}^{-1}\right)$.

The overall transfer coefficient, $K_{\text {overall }}$, in Table 8 was also calculated using the following equation:

$N_{\mathrm{CO}_{2}, \mathrm{~g}}=\frac{Q_{\mathrm{g}}}{A}\left(C_{\mathrm{CO}_{2, \text { in }}}-C_{\mathrm{CO}_{2, \text { out }}}\right)=K_{\text {overall }} \frac{\Delta y l m \cdot P_{\mathrm{T}}}{R T}$

where $Q_{\mathrm{g}}$ is the gas flow rate $\left(\mathrm{m}^{3} \mathrm{~s}^{-1}\right), A$ is the membrane area $\left(\mathrm{m}^{2}\right), P_{\mathrm{T}}$ is the total pressure in the gas phase, and $\Delta y l m$ is the logarithmic mean of the driving force based on the gas phase molar fractions. The $K_{\text {overall }}$ values, as expected, rise when the temperature increases (Table 8).

Table 9 compares the $K_{\text {overall }}$ value obtained at room temperature $(298 \pm 5 \mathrm{~K})$ with some literature values using other solvents in PVDF membrane contactors for $\mathrm{CO}_{2}$ capture. Concerning to Koverall, this work achieved values that were almost one order of
Table 9

$K_{\text {overall }}$ comparison with literature values.

\begin{tabular}{llc}
\hline Reference & Solvent & $K_{\text {overall }}\left(10^{6} \mathrm{~m} \mathrm{~s}^{-1}\right)$ \\
\hline This work & [emim][Ac] & 16.6 \\
{$[42]$} & $1 \mathrm{M} \mathrm{MEA}$ & 0.75 \\
{$[43]$} & $1 \mathrm{M} \mathrm{MEA}$ & 0.93 \\
{$[42]$} & $1 \mathrm{M} \mathrm{DEA}$ & 0.30 \\
{$[44]$} & Distilled water & 4.85 \\
\hline
\end{tabular}

All these references using a PVDF hollow fiber membranes.

magnitude higher than previous works [42-44] with traditional solvents such as monoethanolamine (MEA) and diethylamine (DEA), which are associated with some operational problems due to volatility and solvent losses; problems that ionic liquids eliminate. Also, It is worth recalling that ILs have some important advantages respect to these absorbents such as negligible vapor pressure, high chemical, electrochemical and thermal stability and can be regenerated.

Related to the temperature dependence, the $K_{\text {overall }}$ values $\left(\mathrm{m} \mathrm{s}^{-1}\right)$ obtained with the PVDF fibers, $\mathrm{D}+$ [emim] [Ac], show an increase from $1.6 \cdot 10^{-5}$ to $2.5 \cdot 10^{-5} \mathrm{~m} \mathrm{~s}^{-1}$ in the range of $303-$ $333 \mathrm{~K}$. The overall mass transfer coefficient is favored by temperature increases due to higher chemisorption phenomenon, lower viscosity and higher diffusivity.

The values of $K_{\text {overall }}$ were also transformed by the term (fiber area/shell volume) in order to compare the results obtained with these PVDF fibers, $D+[$ emim] $[A c]$ and the values obtained when another type of commercial membrane contactor was used (Fig. 7): a polysulfone membrane contactor with different packing densities. This PS module has been used due to excellent mechanical strength, high thermal and chemical stability and perfect solubility in many types of solvents $[45,46]$. Fig. 7 shows the trend of $K_{\mathrm{r}}\left(\mathrm{s}^{-1}\right)$ ( $K_{\text {overall }}$ divided by the term fiber area/shell volume), corresponding to the reaction between $\mathrm{CO}_{2}$ and the ionic liquid [emim][Ac] [3,4,8,12-14].

The temperature dependence was slight because the higher temperature impacted the solubility, viscosity and diffusivity of the ionic liquid, although the mass transfer was favored [12].

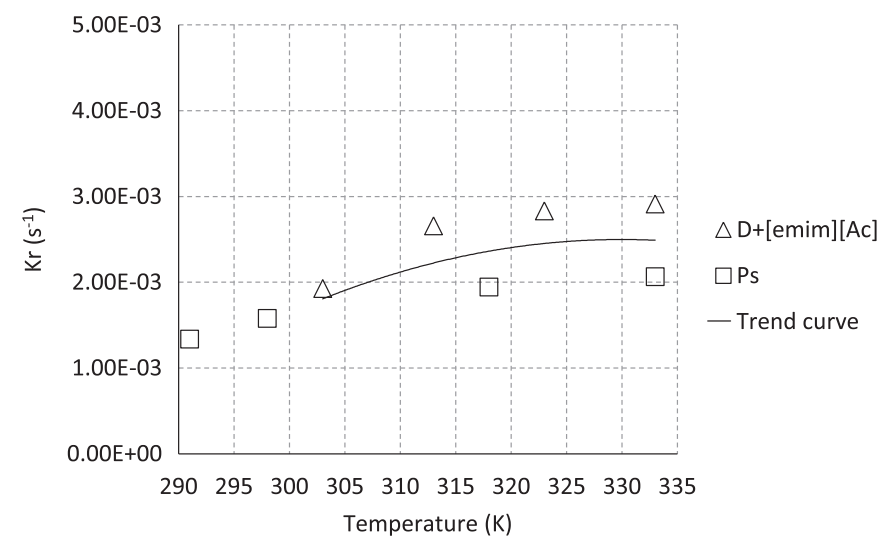

Fig. 7. $\mathrm{Kr}$ comparison with commercial Ps and the $\mathrm{D}+[\mathrm{emim}][\mathrm{Ac}]$ hollow fiber membrane contactor. Ps values adapted from [46]. 


\section{Conclusions}

Four different types of self-made membranes composed of PVDF hollow fibers (coagulation NMP/water) were studied to obtain the best fibers for $\mathrm{CO}_{2}$ absorption. The characterization indicated which type of fiber was more adequate due to its good size, good mechanical properties, high $\mathrm{CO}_{2}$ gas permeability and reasonable bubble point, which were appropriate for a $\mathrm{CO}_{2}$ absorption process in a gas-liquid membrane contactor system.

$\mathrm{C}$ and $\mathrm{D}$ fibers are more adequate for $\mathrm{CO}_{2}$ absorption. For this reason and to improve the absorption rate, two different ionic liquids were immobilized on the two best preforming fibers. On the one hand, the 1-ethyl-3-methylimidazolium ethyl sulfate [emim] $\left[\mathrm{EtSO}_{4}\right]$ ionic liquid presented low viscosity, low toxicity, and low cost. On the other hand, the 1-ethyl-3-methylimidazolium acetate [emim][Ac] ionic liquid had high solubility. These ILs were chosen for this work due to its characteristics, reported in the previous literature $[3,4,8,12-15]$.

Concerning the permeability results, two conclusions could be drawn: (i) the fibers in the dry form presented higher values than those in the wet form, and (ii) when the ionic liquid [emim] $\left[\mathrm{EtSO}_{4}\right]$ was immobilized, the permeability significantly increased by $43 \%$, resulting in $\mathrm{CO}_{2}$ permeance data that were higher than the literature values.

The $\mathrm{CO}_{2}$ capture using PVDF fibers immobilized with the [emim][Ac] ionic liquid achieved a $K_{\text {overall }}$ higher than the values reported in the literature for PVDF hollow fiber membrane contactors using conventional solvents such as MEA and DEA.

Further work is planned for the PVDF fibers immobilized with the [emim] $\mathrm{Ac}]$ ionic liquid to evaluate $\mathrm{CO}_{2}$ capture in a postcombustion environment, as well as to conduct long-term experiments under real operating conditions, including high temperatures. Moreover, the composite fibers designed in this study could also offer interesting potential for other applications, such as gas absorption in physical solvents, liquid degassing by vacuum or gas stripping.

\section{Acknowledgments}

This research has been funded by the Spanish Ministry Economy and Competitiveness (Projects ENE2010-14828 and CTQ201348280-(3-1-R).

\section{References}

[1] J. Albo, A. Irabien, Non-dispersive absorption of $\mathrm{CO}_{2}$ in parallel and cross-flow membrane modules using EMISE, J. Chem. Technol. Biotechnol. 87 (2012) 1502-1507.

[2] D.W. Bailey, P.H.M. Feron, Post-combustion decarbonisation processes, Oil Gas Sci. Technol. 60 (2005) 461-474.

[3] M. Ramdin, T.W. De Loos, T.J.H. Vlugt, State-of-the-art of $\mathrm{CO}_{2}$ capture with ionic liquids, Ind. Eng. Chem. Res. 51 (2012) 8149-8177.

[4] G. Gurau, H. Rodríguez, S.P. Kelley, P. Janiczek, R.S. Kalb, R.D. Rogers, Demonstration of chemisorption of carbon dioxide in 1,3-dialkylimidazolium acetate ionic liquids, Angew. Chem. Int. Ed. 50 (2011) 12024-12026.

[5] E.J. Maginn, Design and Evaluation of Ionic Liquids as Novel $\mathrm{CO}_{2}$ Absorbents, National Energy Technology Laboratory, US, 2004.

[6] Z. Dai, R.D. Noble, D.L. Gin, X. Zhang L. Deng Combination of ionic liquids with membrane technology: a new approach for $\mathrm{CO}_{2}$ separation, J. Membr. Sci. 497 (2016) 1-20.

[7] R. Shindo, M. Kishida, H. Sawa, T. Kidesaki, S. Sato, S. Kanehashi, K. Nagai, Characterization and gas permeation properties of polyimide/ZSM-5 zeolite composite membranes containing ionic liquid, J. Membr. Sci. 454 (2014) 330-338.

[8] J. Blath, N. Deubler, T. Hirth, T. Schiestel, Chemisorption of carbon dioxide in imidazolium based ionic liquids with carboxylic anions, Chem. Eng. J. 181-182 (2012) 152-158.

[9] J. Albo, T. Tsuru, Thin ionic liquid membranes based on inorganic supports with different pore sizes, Ind. Eng. Chem. Res. 53 (2014) 8045-8056.
[10] J. Albo, T. Yoshioka, T. Tsuru, Porous $\mathrm{Al}_{2} \mathrm{O}_{3} / \mathrm{TiO}_{2}$ tubes in combination with 1-ethyl-3-methylimidazolium acetate ionic liquid for $\mathrm{CO}_{2} / \mathrm{N}_{2}$ separation, Sep. Purif. Technol. 122 (2014) 440-448.

[11] E. Santos, J. Albo, A. Irabien, Acetate based supported ionic liquid membranes (SILMs) for $\mathrm{CO}_{2}$ separation: influence of the temperature, J. Membr. Sci. 452 (2014) 277-283.

[12] L. Gomez-Coma, A. Garea, A. Irabien, Non-dispersive absorption of $\mathrm{CO}_{2}$ in $[\mathrm{emim}]\left[\mathrm{EtSO}_{4}\right]$ and [emim] $[\mathrm{Ac}]$ : temperature influence, Sep. Purif. Technol. 132 (2014) 120-125.

[13] M.B. Shiflett, A. Yokozeki, Phase behavior of carbon dioxide in ionic liquids: [emim][acetate], [emim][trifluoroacetate], and [emim][acetate]+[emim][trifluoroacetate] mixtures, J. Chem. Eng. Data 54 (2009) 108-114.

[14] X.L. Papatryfon, N.S. Heliopoulos, I.S. Molchan, L.F. Zubeir, N.D. Bezemer, M. K. Arfanis, A.G. Kontos, V. Likodimos, B. Iliev, G.E. Romanos, P. Falaras, K. Stamatakis, K.G. Beltsios, M.C. Kroon, G.E. Thompson, J. Klöckner, T.J. S. Schubert, CO2 capture efficiency, corrosion properties, and ecotoxicity evaluation of amine solutions involving newly synthesized ionic liquids, Ind. Eng. Chem. Res. 53 (30) (2014) 12083-12102.

[15] A. Arce, H. Rodríguez, A. Soto, Use of a green and cheap ionic liquid to purify gasoline octane boosters, Green Chem. 9 (2007) 247-253.

[16] P. Luis, T. Van Gerven, B. Van Der Bruggen, Recent developments in membrane-based technologies for $\mathrm{CO}_{2}$ capture, Prog. Energy Combust. Sci. 38 (2012) 419-448.

[17] S.H. Lin, C.F. Hsieh, M.H. Li, K.L. Tung, Determination of mass transfer resistance during absorption of carbon dioxide by mixed absorbents in PVDF and PP membrane contactor, Desalination 249 (2009) 647-653.

[18] J. Albo, P. Luis, A. Irabien, Carbon dioxide capture from flue gases using a crossflow membrane contactor and the ionic liquid 1-ethyl-3-methylimidazolium ethylsulfate, Ind. Eng. Chem. Res. 49 (2010) 11045-11051.

[19] M. Mavroudi, S.P. Kaldis, G.P. Sakellaropoulos, A study of mass transfer resistance in membrane gas-liquid contacting processes, J. Membr. Sci. 272 (2006) 103-115.

[20] J.A. Thompson, J.T. Vaughn, N.A. Brunelli, W.J. Koros, C.W. Jones, S. Nair, Mixedlinker zeolitic imidazolate framework mixed-matrix membranes for aggressive $\mathrm{CO}_{2}$ separation from natural gas, Microporous Mesoporous Mater. 192 (2014) 43-51.

[21] S. Farrukh, F.T. Minhas, A. Hussain, S. Memon, M.I. Bhanger, M. Mujahid, Preparation, characterization, and applicability of novel calix[4]arene-based cellulose acetate membranes in gas permeation, J. Appl. Polym. Sci. 131 (6) (2014), http://dx.doi.org/10.1002/APP.39985, 39985 (1-9).

[22] E. Lasseuguette, J.C. Rouch, J.C. Remigy, Hollow-fiber coating: application to preparation of composite hollow-fiber membrane for gas separation, Ind. Eng. Chem. Res. 52 (36) (2013) 13146-13158.

[23] S. Dai, Y. Seol, S. Wickramanayake, D. Hopkinson, Characterization of hollow fiber supported Ionic liquid membranes using microfocus X-ray computed tomography, J. Membr. Sci. 492 (2015) 497-504.

[24] P.T. Nguyen, E. Lasseuguette, Y. Medina-Gonzalez, J.C. Remigy, D. Roizard, E. Favre, A dense membrane contactor for intensified $\mathrm{CO}_{2}$ gas/liquid absorption in post-combustion capture, J. Membr. Sci. 377 (1-2) (2011) 261-272.

[25] N. Goyal, S. Suman, S.K. Gupta, Mathematical modeling of $\mathrm{CO}_{2}$ separation from gaseous-mixture using a hollow-fiber membrane module: physical mechanism and influence of partial-wetting, J. Membr. Sci. 474 (2015) 64-82.

[26] T. Savart, Conception et réalisation de fibres creuses industrielles d'ultrafiltration en poly (fluorure de vinylidène) (PVDF) contenant des copolymères à blocs, Université Toulouse 3, Paul Sabatier, Toulouse, France, 2013.

[27] O. Lorain, J. M. Espenan, J.C. Remigy, J. F. Lahitte, J. C. Rouch, T. Savart, P. Gerard, S. Magnet, Copolymer having amphiphilic blocks, and use thereof for manufacturing polymer filtration membranes, WO2014/139977 (A1), 2014

[28] Y. Medina-Gonzalez, E. Lasseuguette, J.C. Rouch, J.C. Remigy, Improving PVDF hollow fiber membranes for $\mathrm{CO}_{2}$ gas capture, Sep. Sci. Technol. 47 (11) (2012) $1596-1605$.

[29] S. Wickramanayake, D. Hopkinson, C. Myers, L. Hong, J. Feng, Y. Seol, D. Plasynski, M. Zeh, D. Luebke, Mechanically robust hollow fiber supported ionic liquid membranes for $\mathrm{CO}_{2}$ separation applications, J. Membr. Sci. 470 (2014) 52-59.

[30] D.H. Kim, I.H. Baek, S.U. Hong, H.K. Lee, Study on immobilized liquid membrane using ionic liquid and PVDF hollow fiber as a support for $\mathrm{CO}_{2} / \mathrm{N}_{2}$ separation, J. Membr. Sci. 372 (2011) 346-354.

[31] M.B. Shiflett, A. Yokozeki, Phase behavior of carbon dioxide in ionic liquids: [emim][Acetate], [emim][Trifluoroacetate], and [emim][Acetate]+[emim][Trifluoroacetate] mixtures, J. Chem. Eng. Data 54 (2009) 108-114.

[32] J. Albo, E. Santos, L.A. Neves, S.P. Simeonov, C.A.M. Afonso, J.G. Crespo, A. Irabien, Separation performance of $\mathrm{CO}_{2}$ through supported magnetic ionic liquid membranes (SMILMs), Sep. Purif. Technol. 97 (2012) 26-33.

[33] M. Rezaei, A.F. Ismail, S.A. Hashemifard, G.H. Bakeri, T. Matsuura, Experimenta study on the performance and long-term stability of PVDF/montmorillonite hollow fiber mixed matrix membranes for $\mathrm{CO}_{2}$ separation process, Int. J. Greenh. Gas. Control. 26 (2014) 147-157.

[34] R. Naim, A.F. Ismail, Effect of fiber packing density of physical $\mathrm{CO}_{2}$ absorption performance in gas-liquid membrane contactor, Sep. Purif. Technol. 115 (2013) $152-157$.

[35] Matevž. Vospernik, Albin Pintar, Gorazd Bercic, Janez Levec, Mass transfer studies in gas-liquid-solid membrane contactors, Catal. Today 79-80 (2003) 169-179.

[36] M. Alame, A. Abusaloua, M. Pera-Titus, N. Guilhaume, K. Fiaty, A. GiroirFendler, High-performance catalytic wet air oxidation (CWAO) of organic acids 
and phenol in interfacial catalytic membrane contactors under optimized wetting conditions, Catal. Today 157 (2010) 327-333.

[37] E. Chabanon, B. Belaissaoui, E. Favre, Gas-liquid separation processes based on physical solvents: opportunities for membranes, J. Membr. Sci. 459 (2014) $52-61$.

[38] C. Makhloufi, E. Lasseuguette, J.C. Remigy, B. Belaissaoui, D. Roizard, E. Favre, Ammonia based $\mathrm{CO}_{2}$ capture process using hollow fiber membrane contactors, J. Membr. Sci. 455 (2014) 236-246.

[39] T.G. Skog, S. Johansen, M.B. Hägg, Method to prepare lab-sized hollow fiber modules for gas separation testing, Ind. Eng. Chem. Res. 53 (2014) 9841-9848.

[40] A. Ortiz, D. Gorri, T. Irabien, I. Ortiz, Separation of propylene/propane mixtures using $\mathrm{Ag}^{+}$-RTIL solutions. Evaluation and comparison of the performance of gas-liquid contactors, J. Membr. Sci. 360 (2010) 130-141.

[41] P. Luis, A. Garea, A. Irabien, Zero solvent emission process for sulfur dioxide recovery using a membrane contactor and ionic liquids, J. Membr. Sci. 330 (2009) 80-89.

[42] W. Rongwong, R. Jiraratananon, S. Atchariyawut, Experimental study on membrane wetting in gas-liquid membrane contacting process for $\mathrm{CO}_{2}$ absorption by single and mixed absorbents, Sep. Purif. Technol. 69 (2009) $118-125$.

[43] L. Wang, Z. Zhang, B. Zhao, H. Zhang, X. Lu, Q. Yang, Effect of long-term operation on the performance of polypropylene and polyvinylidene fluoride membrane contactors for $\mathrm{CO}_{2}$ absorption, Sep. Purif. Technol. 116 (2009) 300-306.

[44] M. Rahbari-Sisakht, A.F. Ismail, D. Rana, T. Matsuura, D. Emadzadeh, Effect of SMM concentration on morphology and performance of surface modified PVDF hollow fiber membrane contactor for $\mathrm{CO}_{2}$ absorption, Sep. Purif. Technol. 116 (2013) 67-72.

[45] F. Korminouri, M. Rahbari-Sisakht, T. Matsuura, A.F. Ismail, Surface modification of polysulfone hollow fiber membrane spun under different air-gap lengths for carbon dioxide absorption in membrane contactor system, Chem. Eng. J. 264 (2015) 453-461.

[46] L.Gomez-Coma, C.Casado-Coterillo, A.Garea, A.Irabien, Temperature effect in polypropylene and polysulfone hollow fiber membrane contactors using ionic liquids. 21st International Congress of Chemical and Process Engineering Czech Republic. Prague. pp. 23-27, August 2014. 